\title{
CARCINOMA SUPERFICIAL MULTIFOCAL DO PÊNIS. ÊNFASE AO TESTE DO AZUL DE TOLUIDINA
}

\author{
PENILE MULTIFOCAL SUPERFICIAL CARCINOMA. \\ EMPHASIS TO TOLUIDINE BLUE TEST
}

Hélio Begliomini, TCBC-SP ${ }^{1}$

\section{INTRODUÇÃO}

A eritroplasia de Queyrat foi originalmente descrita por Tarnovsky em 1891. Em 1911, Queyrat, dermatologista parisiense, aplicou o termo "eritroplasia" em virtude do seu aspecto avermelhado. Em 1933, Sulzberger e Satenstein reconheceram a associação dessas placas com o carcinoma espinocelular in situ.

Bowen descreveu, em 1912, o carcinoma espinocelular in situ cutâneo, tanto para áreas protegidas, quanto para áreas não-protegidas do sol. Vários relatos têm indicado uma associação entre a doença de Bowen e neoplasias internas, tendo o arsênico como possível fator etiológico em ambas as condições. Tal associação não se aplica ao carcinoma de células espinocelulares do pênis que tem diferentes fatores etiológicos implicados, além de não apresentar múltiplos sítios, como tem sido descrito com a doença de Bowen ${ }^{1}$.

Histologicamente, a eritroplasia de Queyrat tem aspecto similar à doença de Bowen diferenciando-se, por alguns autores, por ter ocorrência genital. Ambas as condições são formadas por células displásicas, característica do carcinoma in situ (neoplasia intra-epitelial) e predispondo ao desenvolvimento do carcinoma espinocelular.

O carcinoma peniano é entidade incomum, sendo responsável por menos de $1 \%$ das neoplasias masculinas nos Estados Unidos. Por sua vez, o carcinoma in situ representa apenas $10 \%$ dos casos diagnosticados de carcinoma peniano, sendo rara a sua metastatização.

O presente trabalho objetiva relatar um caso incomum de carcinoma in situ do pênis com ênfase ao teste do azul de toluidina.

\section{RELATO DO CASO}

F.A.N. 66 anos, branco procurou avaliação urológica por apresentar eliminação de pus peniano. Relatava ser portador de fimose desde criança sem lhe ter incomodado.
Fazia uso de clorpropramida para tratamento de diabetes melitus. Ao exame físico, apresentava prepúcio espesso, esbranquiçado, inelástico, irredutível, com edema crônico e com fissuras, compatível com balanopostite xerótica obliterante. Os exames laboratoriais revelaram-se normais com exceção da glicemia que foi de $168 \mathrm{mg} \%$.

$\mathrm{O}$ paciente foi submetido à circuncisão, sendo detectadas áreas levemente ulceradas, friáveis, eritemato-esbranquiçadas e indolores localizadas na glande e na superfície interna do prepúcio (Figura 1). As lesões não foram resolvidas, apesar do uso de cremes cicatrizantes associados a antibióticos tópicos e orais.

Submetido ao teste do azul-de-toluidina e limpeza com ácido acético (Figura 2), quatro das áreas suspeitas foram biopsiadas, o estudo anatomopatológico revelou, na pele dorsal do pênis e parte dorsal da glande, carcinoma espinocelular in situ. Na pele lateral direita do pênis e região perimeatal da glande, carcinoma espinocelular bem diferenciado superficialmente invasivo (não ultrapassando a lâmina própria).

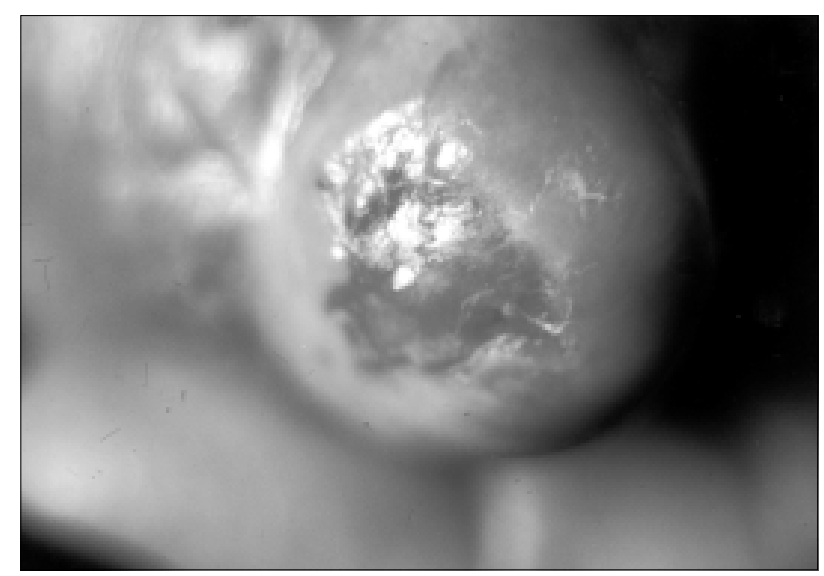

Figura 1 - Úlceras rasas, eritemato-esbranquiçadas na glande e superfície interna do prepúcio.

1. Assistente do Serviço de Urologia do Hospital do Servidor Público do Estado de São Paulo. Mestre em Urologia pela Escola Paulista de Medicina.

Recebido em 1/6/2000

Aceito para publicação em 26/9/2000

Trabalho realizado no Instituto de Medicina Humanae Vitae - UMUVI. 


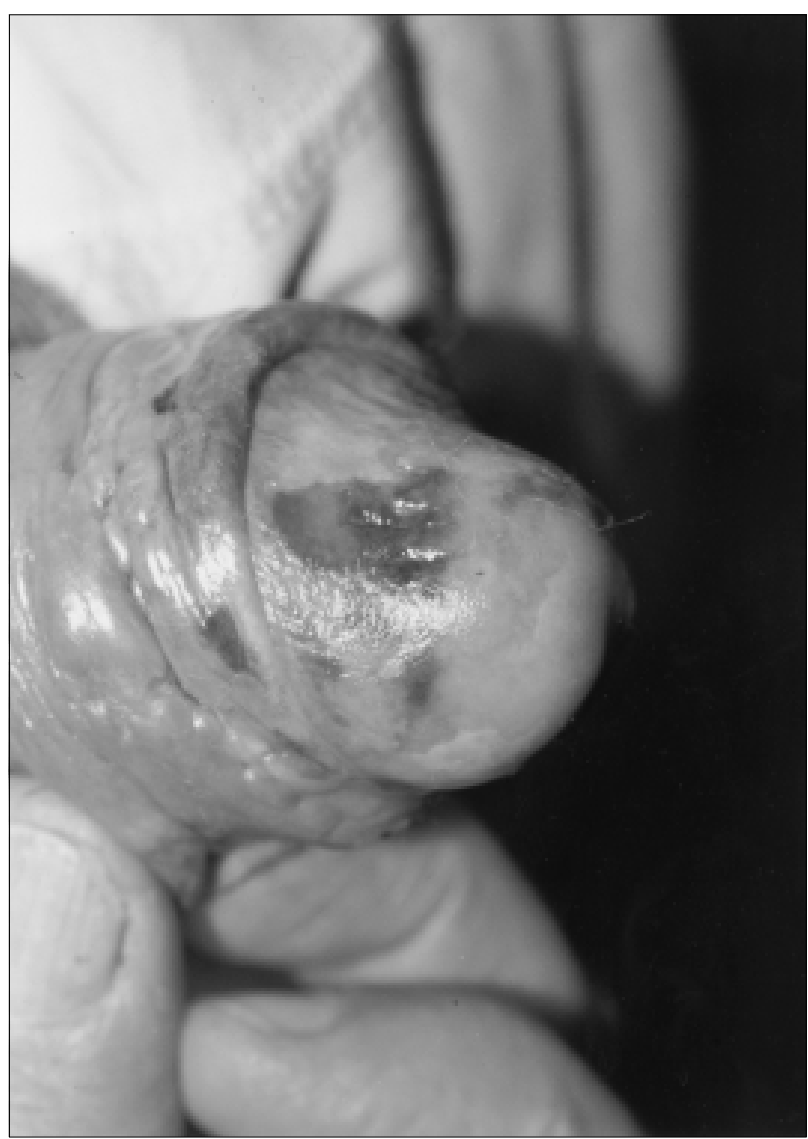

Figura 2 - Lesões evidenciadas pelo teste do azul-de-toluidina.

O paciente foi submetido à penectomia parcial distal (cerca de $3 \mathrm{~cm}$ ) com margens cirúrgicas livres de comprometimento neoplásico no exame de congelação. $\mathrm{O}$ estudo anatomopatológico da peça confirmou os achados da biópsia. O paciente está em seguimento ambulatorial há dois anos, sem evidências de recidivas.

\section{DISCUSSÃO}

A eritroplasia de Queyrat tem como diagnóstico diferencial as seguintes afecções: balanopostite crônica, doença de Paget, hipersensibilidade relacionada a drogas, balanite de Zoon, líquen plano e balanite circinada ${ }^{2}$.
As lesões cutâneas pré-malignas são: corno cutâneo, balanite xerótica obliterante, leucoplasia, papulose bowenóide, tumor de Buschke-Löwenstein, eritroplasia de Queyrat e doença de Bowen.

O teste do azul de toluidina a $1 \%$ pode colaborar no diagnóstico e tratamento de estágios iniciais do carcinoma espinocelular de membranas mucosas (boca, pênis e vagina). Quando esta neoplasia é detectada precocemente, a simples remoção cirúrgica proporciona índices de cura próximos a $100 \%$.

$\mathrm{O}$ fato de as lesões mucosas estarem, geralmente, ocultas da visão e serem assintomáticas ou com discretos sintomas irritativos, constitui dificuldade para o diagnóstico precoce do carcinoma espinocelular de mucosas.

A aplicação do teste do azul-de-toluidina deverá obedecer aos seguintes passos:

- limpeza do genital com compressas úmidas.

- secamento da região com gases evitando-se escoriações das lesões.

- aplicação do azul-de-toluidina a $1 \%$ na região suspeita e áreas circunjacentes.

- limpeza da região com compressas embebidas em solução de ácido acético a $1 \%$ por um minuto para remover o corante não aderente.

- lava-se a área com água.

- seca-se a área novamente.

O teste é considerado positivo se a mucosa retiver a coloração azul escura, tanto de modo completo como pontilhado. Por sua vez, a área é considerada negativa se o ácido acético remover a coloração azul. Na dúvida, aplicase novamente o ácido acético com cotonete, considerandose negativo, quando houver a remoção do corante.

$\mathrm{O}$ azul de toluidina é um corante nuclear acidófilo e metacromático. Será retido por qualquer tecido com grande conteúdo nuclear, sem ser um corante específico para células neoplásicas. No contexto clínico, a maior parte das lesões eritomatosas da mucosa não retém o corante, talvez por causa da hiperqueratose associada e pela integridade da membrana. Deve-se salientar como exceção, a positividade do teste a certas formas do condiloma acuminado ${ }^{3}$.

Há várias opções de tratamento descritas, tais como: creme com 5-fluorouracil, crioterapia, radioterapia, YAG laser, laser com $\mathrm{CO}_{2}$, exérese da lesão e penectomia parcial $^{1-3}$

No presente caso, o teste do azul-de-toluidina evidenciou a multicentricidade das lesões com opção pela penectomia parcial.

\begin{abstract}
The author reports a case of penile multifocal superficial carcinoma in a white 66 years old male. The lesions on glans penis and prepuce were asymptomatic. Their appearence were plain reddish ulceration, irregular margins which became evident after circumcision. There was no palpable groin lymph node. The toluidine blue test was useful for guiding biopsies. A partial penectomy was undertaken with free surgical margins of tumor. In a followup of two years, penil erectile function is preserve with no tumor recurrence.
\end{abstract}

Key Words: Penile in situ carcinoma; Queyrat's erithroplasy; Toluidine blue test. 


\section{REFERÊNCIAS}

1. Kaye V, Zhang G, Dehner LP, et al. - Carcinoma in situ of penis. Urology 1990, 36: 479-482.

2. Begliomini H., Cruz AG, França LCM. Balanite plasmocitária de Zoon. Uma doença pouco conhecida. Diagnóstico diferencial com a eritroplasia de Queyrat. J.Bras.Urol. 1994, 20: 193-195.
3. Eliezri YD. The toluidine blue test: An aid in the diagnosis and treatment of early squamous cell carcinomas of mucosus membranas. J Am Acad Dermatol 1988, 18: 1339-1349.

Endereço para Correspondência

Dr. Hélio Begliomini

Rua Bias, 234

02372-010 - São Paulo - SP 